\title{
Preconditioning diabetic mesenchymal stem cells with myogenic medium increases their ability to repair diabetic heart
}

\author{
Mohsin Khan ${ }^{\dagger}$, Fatima Ali ${ }^{\dagger}$, Sadia Mohsin, Shoaib Akhtar, Azra Mehmood, Mahmood S Choudhery, \\ Shaheen N Khan and Sheikh Riazuddin ${ }^{*}$
}

\begin{abstract}
Introduction: Mesenchymal stem cells (MSCs) have the potential for treatment of diabetic cardiomyopathy; however, the repair capability of MSCs declines with age and disease. MSCs from diabetic animals exhibit impaired survival, proliferation, and differentiation and therefore require a strategy to improve their function. The aim of the study was to develop a preconditioning strategy to augment the ability of MSCs from diabetes patients to repair the diabetic heart.

Methods: Diabetes was induced in C57BL/6 mice (6 to 8 weeks) with streptozotocin injections $(55 \mathrm{mg} / \mathrm{kg}$ ) for 5 consecutive days. MSCs isolated from diabetic animals were preconditioned with medium from cardiomyocytes exposed to oxidative stress and high glucose ( $\mathrm{HG} / \mathrm{H}-\mathrm{CCM})$.

Results: Gene expression of VEGF, ANG-1, GATA-4, NKX2.5 MEF2C, PCNA, and eNOS was upregulated after preconditioning with $\mathrm{HG} / \mathrm{H}-\mathrm{CCM}$, as evidenced by reverse transcriptase/polymerase chain reaction (RT-PCR). Concurrently, increased AKT phosphorylation, proliferation, angiogenic ability, and reduced levels of apoptosis were observed in $\mathrm{HG} / \mathrm{H}-\mathrm{CCM}$-preconditioned diabetic MSCs compared with nontreated controls. HG/H-CCMpreconditioned diabetic-mouse-derived MSCs (dmMSCs) were transplanted in diabetic animals and demonstrated increased homing concomitant with augmented heart function. Gene expression of angiogenic and cardiac markers was significantly upregulated in conjunction with paracrine factors (IGF-1, HGF, SDF-1, FGF-2) and, in addition, reduced fibrosis, apoptosis, and increased angiogenesis was observed in diabetic hearts 4 weeks after transplantation of preconditioned dmMSCs compared with hearts with nontreated diabetic MSCS.
\end{abstract}

Conclusions: Preconditioning with HG/H-CCM enhances survival, proliferation, and the angiogenic ability of dmMSCs, augmenting their ability to improve function in a diabetic heart.

Keywords: Mesenchymal stem cells, Diabetic heart, Preconditioning, Oxidative stress

\section{Introduction}

Diabetes mellitus increases the incidence of heart failure and mortality in diabetes patients [1]. Diabetic cardiomyopathy is associated with diastolic and systolic impairments, leading to endothelial dysfunction, alterations in glucose metabolism, increased fatty acid oxidation, and generation of free radicals [2-4]. Endothelial dysfunction significantly alters angiogenesis in a diabetic

\footnotetext{
* Correspondence: riazuddin@aimrc.org

${ }^{\dagger}$ Equal contributors

National Center of Excellence in Molecular Biology, University of the Punjab, 87-West Canal Bank Road, Lahore, Pakistan
}

heart because of impaired nitric oxide production [5] that further contributes to the etiology of the disease. Restoration of neoangiogenesis within a diabetic heart remains a desirable treatment modality and may augment the depleted diabetic heart function.

Mesenchymal stem cells (MSCs) exhibit multilineage differentiation potential [6-8] and have been widely used in cell-based therapies for the alleviation of a number of impairments, including cardiovascular disorders $[9,10]$. Even though MSCs represent a feasible choice for myocardial repair, recent evidence implies that the capability of MSCs to repair damaged tissues declines with age and 
disease [11-14]. A number of preconditioning strategies have been used to enhance depleted stem cell function by treatment with growth factors, hypoxic shock, and antiaging compounds $[15,16]$. Interestingly, hypoxic preconditioning has been shown to increase mobilization, adhesion, survival, and cardiomyogenic differentiation of MSCs [17-19]. In addition, the age-depleted angiogenic ability of MSCs can be enhanced by hypoxic preconditioning, leading to improved therapeutic efficiency of aged MSCs [20].

Onset of diabetes leads to premature aging of stem cells [21] and is associated with impaired proliferation, paracrine ability, and myogenic differentiation of bone marrow-derived MSCs [22]. Diabetic MSCs demonstrate low differentiation ability in culture conditions, yet preconditioning strategies have not been exploited to improve their function and thus represent an area of further research. In the present study, we demonstrated that diabetic-mouse MSCs (dmMSCs) cultured under high glucose and oxidative stress have increased survival, proliferation, and angiogenic ability. Furthermore, adoptive transfer of preconditioned dmMSCs leads to significant improvement in diabetic heart function.

\section{Materials and methods Animals}

The animals used in this study were treated as per Instructions of the Care and Use of Laboratory Animals published by the U.S. National Institutes of Health (NIH Publication No. 85-23, revised 1985), and the study was approved by the Institutional Review Committee at the National Center of Excellence in Molecular Biology, Lahore, Pakistan.

\section{Cell culture}

MSCs were isolated and cultured as described [23]. In brief, 60 days after diabetes induction, animals were anesthetized with a single intraperitoneal pentobarbital (40 $\mathrm{mg} / \mathrm{kg}$ ) injection. MSCs from tibias and femurs of C57BL/6 mice were isolated and cultured in Iscove Modified Dulbecco Medium (IMDM) supplemented with $20 \%$ fetal bovine serum (FBS), penicillin $(100 \mathrm{U} / \mathrm{ml})$, and streptomycin $(100 \mu \mathrm{g} / \mathrm{ml})$. Sprague-Dawley rat pups $(n=10)$ were anesthetized on ice followed by wholeheart removal for cardiomyocyte isolation by using a cardiomyocytes isolation system (Worthington Biomedical Corporation, NJ USA), as described previously [14].

\section{Oxidative stress}

Cardiomyocytes were divided into four experimental treatment groups: (I) low glucose (LG; glucose, $5 \mathrm{mM}$ ); (II) low glucose $\mathrm{H}_{2} \mathrm{O}_{2}$ (LG/H); (III) high glucose (HG; glucose, $25 \mathrm{mM}$ ); and (IV) high glucose $\mathrm{H}_{2} \mathrm{O}_{2}(\mathrm{HG} / \mathrm{H})$. Oxidative stress was induced with $\mathrm{H}_{2} \mathrm{O}_{2}(100 \mu M)$ for 60 and 90 minutes in serum-free medium. Cardiomyocytes kept in glucose and serum-free medium were used as the control.

\section{Enzyme-linked immunosorbent assay}

VEGF concentration was determined by using VEGF ELISA kit (Invitrogen, CA USA), according to the manufacturer's protocol. Medium from cardiomyocyte cultures after no treatment and oxidative stress was collected and centrifuged at 2,000 $g$ for 10 minutes at room temperature.

\section{Preconditioning of diabetic-mouse-derived MSCs}

Preconditioning of diabetic-mouse-derived MSCs (dmMSCs) was done by using two strategies. In the first strategy, dmMSCs were preconditioned with cardiomyogenic medium (CCM) comprising the four treatments described that is, (I) LG, (II) LG/ H, (III) $\mathrm{HG}$, and (IV) $\mathrm{HG} / \mathrm{H}$.

In the second strategy, we used VEGF pretreatment in concentrations corresponding to ELISA readouts in four CCM treatment groups with the aim to differentiate the effect of cardiomyogenic medium from the solitary effect of VEGF on dmMSCs function. VEGF concentrations in the four groups were as follows: (I) $0.1 \mathrm{ng} / \mathrm{ml}$, (II) $0.05 \mathrm{ng} / \mathrm{ml}$ (II), (III) $0.065 \mathrm{ng} / \mathrm{ml}$, and (IV) $0.145 \mathrm{ng} / \mathrm{ml}$. Preconditioning was done for 48 hours, and nontreated dmMSCs were used as controls.

\section{Gene-expression profiling}

RNA was extracted from normal MSCs, nontreated dmMSCs, preconditioned dmMSCs, and heart tissue samples by using Trizole reagent (Invitrogen, USA) and quantified with an ND-1000 spectrophotometer (NanoDrop Technologies, DE USA). cDNA synthesis was performed from $1 \mu \mathrm{g}$ RNA by using a reverse transcriptase kit (Invitrogen). Real-time RT-PCR was carried out by using SYBR Green PCR Super Mix (BioRad, CA USA), 8 $\mathrm{m} M$ of each primer, and 100 to $500 \mathrm{ng} / \mathrm{ml}$ of template cDNA on BioRad System iQ5. The relative ratio and standard deviation between the normal and treated samples were calculated by using the comparative $\mathrm{Ct}$ method (DD $\mathrm{Ct}$ value), as recommended by the BioRad iQ5system. RT-PCR analysis was carried out for IGF-1, p16INK4a, p66shc, p53, VEGF, ANG-1, NF$\kappa B, M E F 2 c$, GATA-4, NKx2.5, CD31, CD34, PCNA, eNOS, and $i N O S$ on a GeneAmp PCR system 9700 (Applied Biosystems, CA USA). GAPDH was used as an internal control, and bands were quantified by using ImageJ. The sequences $\left(5^{\prime}\right.$ to $\left.3^{\prime}\right)$ for the primer pairs and their product lengths (bp) are mentioned in Table 1. 
Table 1 Primer sequences

\begin{tabular}{|c|c|c|}
\hline Genes & Product size (bp) & Sequences ( $5^{\prime}$ to $\left.3^{\prime}\right)$ \\
\hline GAPDH (f) & \multirow{2}{*}{370} & CTCTTGCTCTCAGTATCCTTG \\
\hline GAPDH (r) & & GCTCACTGGCATGGCCTTCC \\
\hline IGF-1 ( & \multirow{2}{*}{166} & AGGCTATGGCTCCAGCATTC \\
\hline IGF-1 (r) & & AGTCTTGGGCATGTCAGTGTC \\
\hline HGF $(f)$ & \multirow{2}{*}{167} & TCACACAGAATCAGGCAAGACT \\
\hline HGF (r) & & AAGGGGTGTCAGGGTCAA \\
\hline SDF-1 (f) & \multirow{2}{*}{122} & CGGCTGAAGAACAACAACAG \\
\hline SDF-1 (r) & & GGGGGTCTACTGGAAAGTCC \\
\hline FGF-2 (f) & \multirow{2}{*}{154} & TGTCTATCAAGGGAGTGTGTGC \\
\hline FGF-2 (r) & & CAACTGGAGTATTTCCGTGACC \\
\hline ANG1 (f) & \multirow{2}{*}{143} & GACACCTTGAAGGAGGAGAAAG \\
\hline ANG1 (r) & & GTGTCCATGAGCTCCAGTTGT \\
\hline VEGF (f) & \multirow{2}{*}{200} & ACCCCGACGAGATAGAGTACAT \\
\hline VEGF (r) & & СTTCTAATGCCCCTCCTTGT \\
\hline GATA-4 (f) & \multirow{2}{*}{90} & ССTCTCCCAGGAACATCAAA \\
\hline GATA-4 (r) & & ACCCATAGTCACCAAGGCTG \\
\hline NKx $2.5(f)$ & \multirow{2}{*}{147} & GGTCTCAATGCCTATGGCTAC \\
\hline NKx $2.5(r)$ & & GTTCACGAAGTTGCTGTTGG \\
\hline MEF2C (f) & \multirow{2}{*}{178} & CACGCCTGTCACCTAACATCC \\
\hline MEF2C (r) & & TGTTAGCTCTCAAACGCCACAC \\
\hline PCNA (f) & \multirow{2}{*}{110} & TGACCCTCACCGATACAACA \\
\hline PCNA (r) & & CTGTACAGCACAGCCACGTT \\
\hline p53 (f) & \multirow{2}{*}{157} & AGCATCTTATCCGGGTGGAAG \\
\hline p53 (r) & & CCCATGCAGGAGCTATTACACA \\
\hline CD31 (f) & \multirow{2}{*}{120} & CCCAGTGACATTCACAGACA \\
\hline CD31 (r) & & ACCTTGACCCTCAGGATCTC \\
\hline CD34 (f) & \multirow{2}{*}{200} & GGGTAGCTCTCTGCCTGATG \\
\hline CD34 (r) & & TCTCTGAGATGGCTGGTGTG \\
\hline$N F-K B(f)$ & \multirow{2}{*}{200} & GCACCTGTTCCAAAGAGCAC \\
\hline$N F-K B(r)$ & & GTGGAGTGAGACATGGACACAC \\
\hline iNOS ( & \multirow{2}{*}{116} & GCTACACTTCCAACGCAACA \\
\hline iNOS (r) & & CATGGTGAACACGTTCTTGG \\
\hline eNOS (f) & \multirow{2}{*}{123} & TGACCCTCACCGATACAACA \\
\hline eNOS (r) & & CTGTACAGCACAGCCACGTT \\
\hline
\end{tabular}

Analysis of preconditioned diabetic-mouse-derived MSCs Two groups of preconditioned dmMSCs were selected for further analysis on the basis of RT-PCR results (that is, HG/H-CCM and the VEGF $(0.065 \mathrm{ng} / \mathrm{ml})$ groups.

\section{Cell viability}

Viability of dmMSCs after preconditioning was done with the trypan blue exclusion method. The preconditioned (CCM and VEGF preconditioned) diabetic cells and diabetic nontreated cells were trypsinized, centrifuged, and counted by using a hemocytometer.

\section{Lactate dehydrogenase assay}

LDH assay was used to determine the extent of cell damage in both preconditioned groups by using the LDH assay kit (Sigma T0X-7, MO USA) according to the manufacturer's instructions. Absorbance values were measured by using Spectra max PLUS 384 (Molecular Devices, CA USA) at $490 \mathrm{~nm}$.

\section{Apoptosis}

Apoptosis was measured in nontreated and preconditioned dmMSCs by using the Phycoerythrin Annexin-V kit (Abcam, CA USA). In brief, $6 \times 10^{4}$ diabetic MSCs were plated in a 24-well plate (Corning, MA USA) and treated with $\mathrm{HG} / \mathrm{H}-\mathrm{CCM}$ and VEGF $(0.065 \mathrm{ng} / \mathrm{ml})$ groups followed by $\mathrm{H}_{2} \mathrm{O}_{2}(100 \mu M)$ treatment for $90 \mathrm{mi}-$ nutes to induce apoptosis. The Annexin- $\mathrm{V}^{+}$cells were then counted at random in five fields per triplicate well for each treatment.

\section{Immunoblot}

Total protein was extracted from both preconditioned groups and nontreated dmMSCs by using RIPA buffer and estimated with Bradford protein assay (Bio-Rad, CA USA) followed by separation on 10\% SDS-PAGE. The membrane was then incubated overnight at $4^{\circ} \mathrm{C}$ with AKT (Santa Cruz, CA USA), phospo-AKT serine 473 (Abcam), and $\beta$ actin (Abcam, CA USA). Anti-mouse and anti-rabbit secondary antibodies (Abcam) HRP-conjugated were applied for 1 hour, and bands were visualized with an enhanced chemiluminescence (ECL) detection system (Amersham Pharmacia Biotech, PE USA).

\section{Cell proliferation}

A cell-proliferation assay was carried out with a XTT (sodium 3-[1- \{phenylaminocarbonyl\}-3,4-tetrazolium]-bis \{4-methoxy-6-nitro\} benzene sulfonic acid hydrate) cell proliferation kit, according to the manufacturer's protocol (Roche, IN USA). In brief, $4 \times 10^{3} \mathrm{dmMSCs}$ were plated in triplicate in a 96-well plate (Corning, USA) overnight in IMDM supplemented with $20 \%$ FBS in an incubator at $37^{\circ} \mathrm{C}$ and $5 \% \mathrm{CO}_{2}$. Absorbance was taken at $450 \mathrm{~nm}$ by using Spectra max PLUS 384 (Molecular Devices), with $650 \mathrm{~nm}$ as the reference wavelength.

\section{In vitro tube-forming assay}

In vitro angiogenic potential of both preconditioned groups and nontreated dmMSCs was assessed with a gelatinous protein mixture (Matrigel) assay (BD Bioscience, CA USA), as described previously [23]. In brief, $8 \times 10^{3}$ cells from each treatment group were plated on Matrigelcoated wells and incubated at $37^{\circ} \mathrm{C}$ in $5 \% \mathrm{CO}_{2}$. The formation of tubular network was examined after 48 hours. The images were taken in a phase-contrast microscope (IX-51, 
Olympus, Tokyo Japan) equipped with a digital camera, DP-71 (Olympus).

\section{Nitric oxide activity}

NOS activity was determined with an NOS colorimetric assay kit (Oxford Biomedical Research, NB 78, Upper Heyford, UK) according to the manufacturer's instructions. In brief, protein was isolated by using lysis buffer from both preconditioned groups and nontreated dmMSCs to measure NOS activity. Absorbance values were measured by using Spectra max PLUS 384 (Molecular Devices) at $540 \mathrm{~nm}$

\section{Diabetic cardiomyopathy model for cell transplantation}

Diabetes was induced in C57BL/6 male mice by streptozotocin administration, as described previously [23]. In brief, diabetes was induced in C57BL/6 wild-type mice (6 to 8 weeks old) by intraperitoneal injection of streptozotocin $(55 \mathrm{mg} / \mathrm{kg})$ for 5 consecutive days. Because streptozotocin metabolizes within 24 hours, mice were housed with absorbent bedding and food and water ad libitum. At day 16 after the initial injection, mice were weighed, and their blood glucose level was measured. Only streptozotocin-induced diabetic mice with blood glucose levels $>300 \mathrm{mg} / \mathrm{dl}$ were included in the study. Mice after 2 months of diabetes induction were divided into four groups $(n=6)$. Mice in group I served as normal control; group II, as diabetic control injected with saline; group III, as diabetic animals transplanted with nontreated dmMSCs; and group IV, as diabetic animals transplanted with preconditioned dmMSCs. In brief, mice were anesthetized with a single intraperitoneal injection of pentobarbital, and the adequacy of anesthesia was monitored by animal-reflex responses to stimuli. The heart was exposed by left-side limited thoracotomy, and cells were transplanted into the left ventricle. Mice were given subcutaneous buprenorphine $(0.1 \mathrm{mg} / \mathrm{kg})$ injections before the procedure and 24 hours after surgery. Cell concentration used was $1 \times 10^{6} / \mathrm{ml}$, and animals were given intramyocardial injections of MSCs $(10 \mu \mathrm{l} \sim$ 100,000 cells/animal) at two distinct sites in the left ventricle.

\section{Assessment of heart function}

Mice were anesthetized with sodium pentobarbital (40 $\mathrm{mg} / \mathrm{kg}$ ), and hemodynamic function was assessed by using the Millar apparatus (Millar Instruments, Inc., Houston, TX, USA), as described previously [24]. Left ventricle $(\mathrm{LV})$ systolic function was evaluated with $\mathrm{P}_{\max }$, $\mathrm{dp} / \mathrm{dt}_{\max }$, and arterial elastance. LV diastolic function was evaluated with end-diastolic pressure and $\mathrm{dp} / \mathrm{dt}_{\mathrm{min}}$. Analysis was carried out by using the Millar PVAN software (version 3.3).

\section{Fibrosis}

Histologic analysis was performed to determine collagen deposition in the diabetic heart. Heart sections were stained with Masson trichrome stain, and 10 random fields were selected and photographed with light microscopy at $200 \times$ magnification. The extent of fibrosis in the respective images was quantified by using Image $J$ analysis software.

\section{Immunohistochemistry}

Mice were anesthetized and killed by cervical dislocation 4 weeks after MSC injections. The hearts were removed, and sections were analyzed for the detection of cleaved caspase-3 and eNOS through application of enzymelabeled polymer (Vector ImmPRESS kit; Vector Laboratories, CA USA). The frozen tissue was cut into $5-\mu \mathrm{m}$ sections, fixed with $4 \%$ formaldehyde, and permeabilized by using $0.2 \%$ Triton $\mathrm{X}-100$. Sections were treated with $3 \%$ $\mathrm{H}_{2} \mathrm{O}_{2}$ for 10 minutes to block endogenous peroxidase activity, followed by blocking in 5\% donkey serum for 1 hour at room temperature. Sections were incubated overnight with primary antibodies of polyclonal rabbit anticaspase-3 antibody (Santa Cruz Biotechnology) and a rabbit polyclonal anti-eNOS antibody (Abcam) and treated with enzyme horseradish peroxidase (HRP)-conjugated specific secondary antibodies. Sections were incubated with chromogen substrate 3,3'-diaminobenzidine tetrahydrochloride (DAB) solution and counterstained with the Weigert Iron Hematoxylin solution to stain the nuclei. Capillary density was measured by staining sections from control and transplanted groups with $\alpha$-smooth muscle actin ( $\alpha$-SMA) (Sigma-Aldrich, MO USA), and small arterioles per five random fields of each section were counted.

\section{Statistical analysis}

Statistical analysis was performed with Graph Pad Prism-5 software and SPSS software. All data values are expressed as mean \pm SEM. The comparison between more than two parameters was assessed with ANOVA with the Bonferroni post hoc test. The comparison between two groups was performed by using a Student $t$ test. $P<0.05$ was considered significant.

\section{Results}

Preconditioning of diabetic-mouse-derived MSCs

Diabetic-mouse-derived MSCs (dmMSCs) were isolated from diabetic mice 60 days after induction of diabetes and confirmed by blood glucose levels $>300 \mathrm{mg} / \mathrm{dl}$ (Figure 1A). Characterization of dmMSCs demonstrated increased levels of p16INK4a, p66shc, and p53 concomitant with decreased expression of IGF-1, VEGF, and $A n g-1$, compared with normal MSCs, as evidenced by RT-PCR analysis (Figure 1B, C). The dmMSCs were preconditioned with Conditioned Cardiomyogenic Medium 


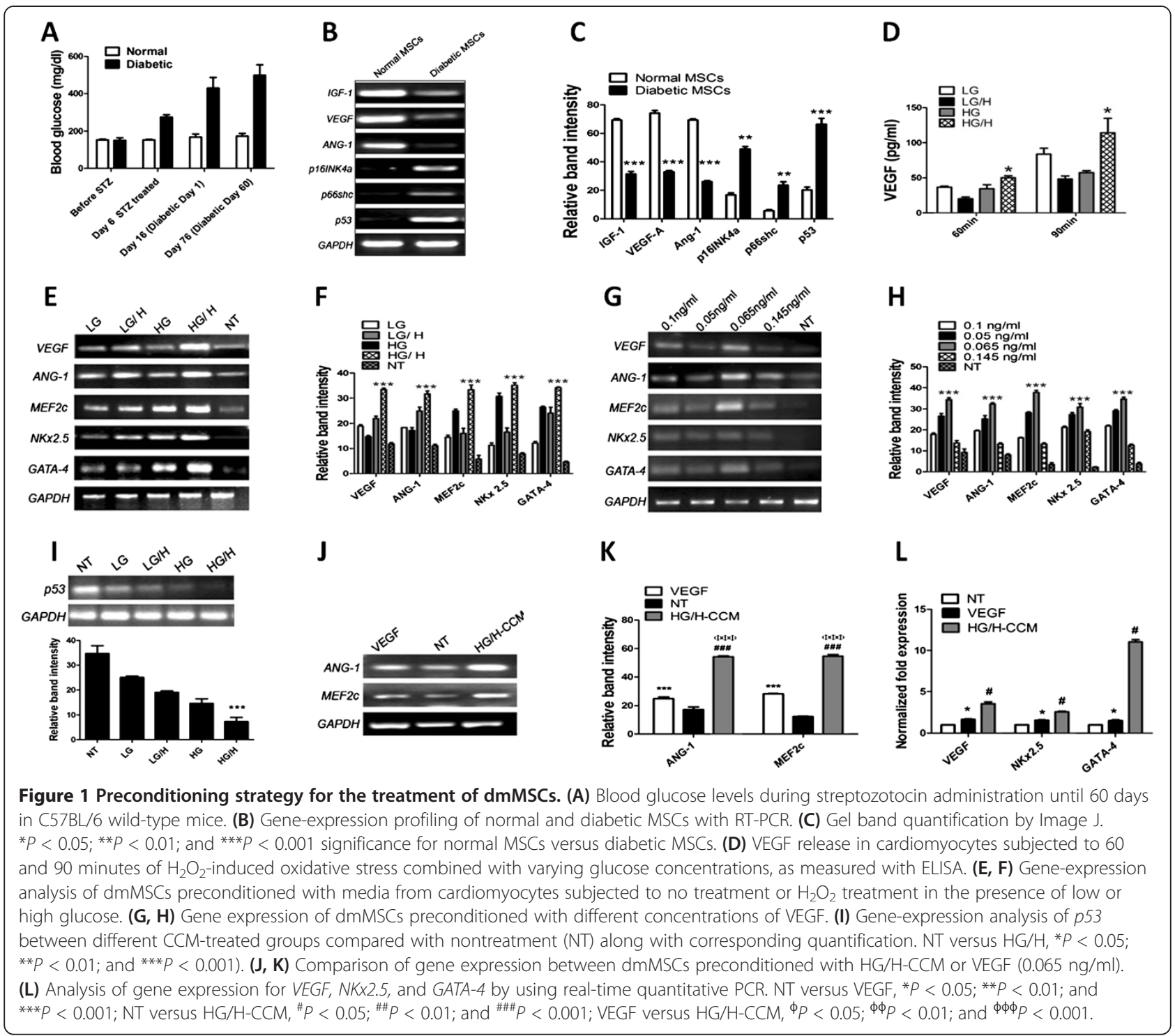

(CCM) to improve dmMSCs function. CCM was prepared by induction of oxidative stress in neonatal rat cardiomyocytes (NRCMs) in combination with low glucose $(5.5 \mathrm{mM})$ and high glucose $(25 \mathrm{mM})$. Results showed that VEGF release increased significantly after 90 minutes of $\mathrm{H}_{2} \mathrm{O}_{2}$ induced oxidative stress compared with 60 minutes in NRCMs (Figure 1D). In contrast, VEGF levels were not detected in nontreated cardiomyocytes kept in glucose and serum-free medium (data not shown). Because 90 minutes of oxidative stress resulted in maximal VEGF release, it was selected as the optimal treatment to be used in combination with high and low glucose for subsequent experiments.

Alternatively, to determine whether VEGF alone can be used as a comparable preconditioning strategy to treatment with CCM, dmMSCs were preconditioned with various concentrations of VEGF corresponding to VEGF ELISA readout after exposure of NRCMs to various treatments, as described earlier.

Gene-expression analysis of angiogenic and cardiac markers was done for all groups of CCM- and VEGF-treated dmMSCs by RT-PCR, whereas nontreated dmMSCs were used as controls. Elevated levels of VEGF, ANG-1 (angiogenic markers), MEF2c, NKx2.5, and GATA-4 (cardiac transcription factors) were observed in the HG/H-CCM group (Figure 1E, F) compared with all other CCM treatment groups. Among the VEGF treatment groups, 0.065 $\mathrm{ng} / \mathrm{ml}$ VEGF concentration resulted in significantly higher levels of the same angiogenic markers and cardiac transcription factors mentioned earlier compared with other VEGF concentrations and the diabetic nontreated group (Figure 1G, H). Furthermore, a significant decline in 
p53 expression was observed in dmMSCs treated with HG/H-CCM compared with all other treatment groups (Figure 1I). Determine the best preconditioning strategy, dmMSCs were treated with HG/H-CCM or $0.065 \mathrm{ng} / \mathrm{ml}$ VEGF and analyzed with RT-PCR for angiogenic and cardiac-specific markers. Gene-expression analysis results indicated a significant increase in VEGF, ANG-1, MEF2c, $N K x 2.5$, and GATA-4 after treatment with HG/H-CCM compared with $0.065 \mathrm{ng} / \mathrm{ml}$ VEGF and the diabetic nontreated group (Figure 1J to L).

\section{CCM preconditioning promotes survival and proliferation of dmMSCs}

The effect of preconditioning on survival was analyzed with immunoblot for $A K T$ and phospho $A K T$. In vitro experiments showed that the HG/H-CCM preconditioned group significantly increased $A K T$ phosphorylation compared with VEGF $(0.065 \mathrm{ng} / \mathrm{ml})$ or nontreated dmMSCs (Figure 2A, B). Increased cell viability was observed in $\mathrm{HG} / \mathrm{H}-\mathrm{CCM}(76 \% \pm 5.54 \%)$ compared with VEGF $(45 \% \pm 3.7 \%)$ and nontreated dmMSCs $(28 \% \pm 1.4 \%)$, evidenced by the trypan-blue exclusion assay (Figure $2 \mathrm{C}$ ). Cellular damage evidenced by the LDH-release assay was significantly reduced after $\mathrm{HG} / \mathrm{H}-\mathrm{CCM}(18 \% \pm 3.5 \%)$ treatment compared with VEGF $(48 \% \pm 2.3 \%)$ and nontreated dmMSCs $(66 \% \pm 3.4 \%)$ (Figure 2D). Concurrently, a significantly low number of Annexin $-\mathrm{V}^{+}$cells was observed in $\mathrm{HG} / \mathrm{H}-\mathrm{CCM}(6 \% \pm 1.88 \%)$ compared with VEGF $(9 \% \pm 1.4 \%)$ and nontreated dmMSCs $(20 \% \pm$ 6.1\%) (Figure $2 \mathrm{G}$ ).

Gene expression of PCNA was observed to be significantly increased after $\mathrm{HG} / \mathrm{H}-\mathrm{CCM}$ treatment versus VEGF versus nontreated dmMSCs (Figure 2E, F). In addition, cell proliferation was assessed after treatment with $\mathrm{HG} / \mathrm{H}-\mathrm{CCM}$ and VEGF $(0.065 \mathrm{ng} / \mathrm{ml})$. Preconditioning with $\mathrm{HG} / \mathrm{H}-\mathrm{CCM}$ resulted in significantly higher proliferation at 24 and 48 hours $(2.61 \pm 0.10 ; 3.1 \pm 0.14)$ followed by VEGF treatment $(1.44 \pm 0.84 ; 2.0 \pm 0.96)$ and nontreated dmMSCs $(1.2 \pm 0.11 ; 1.74 \pm 0.12)$ (Figure 2H).

\section{Increased angiogenic ability of dmMSCs after CCM preconditioning}

The effect of HG/H-CCM or VEGF preconditioning on the ability of dmMSCs for tube formation was assessed by their culture on Matrigel. The in vitro tube-formation ability of dmMSCs was significantly improved in the $\mathrm{HG} / \mathrm{H}-\mathrm{CCM}$-conditioned group compared with VEGF (0.065 ng/ml) and nontreated dmMSCs (Figure 3A through D). Significant upregulation of angiogenic

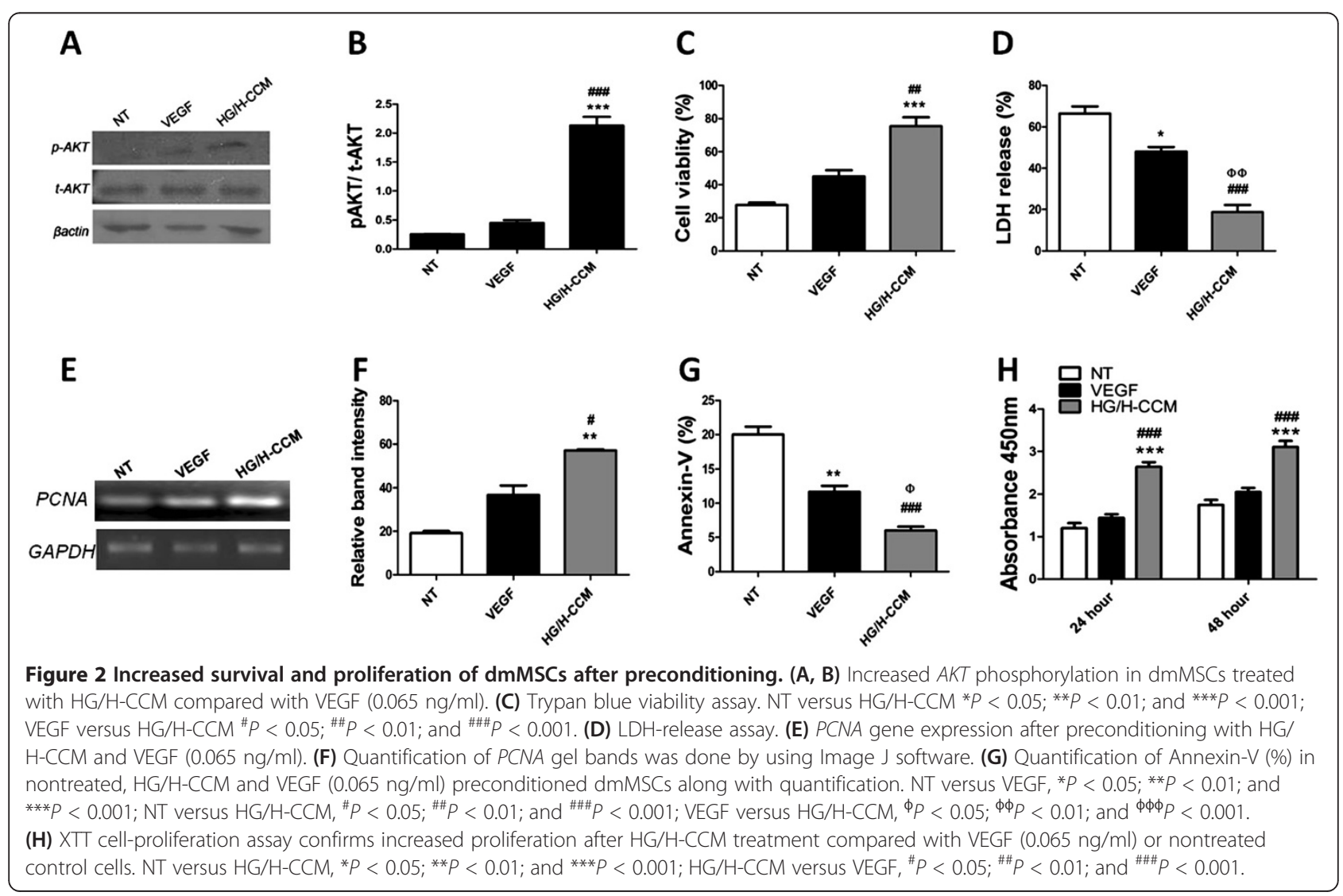




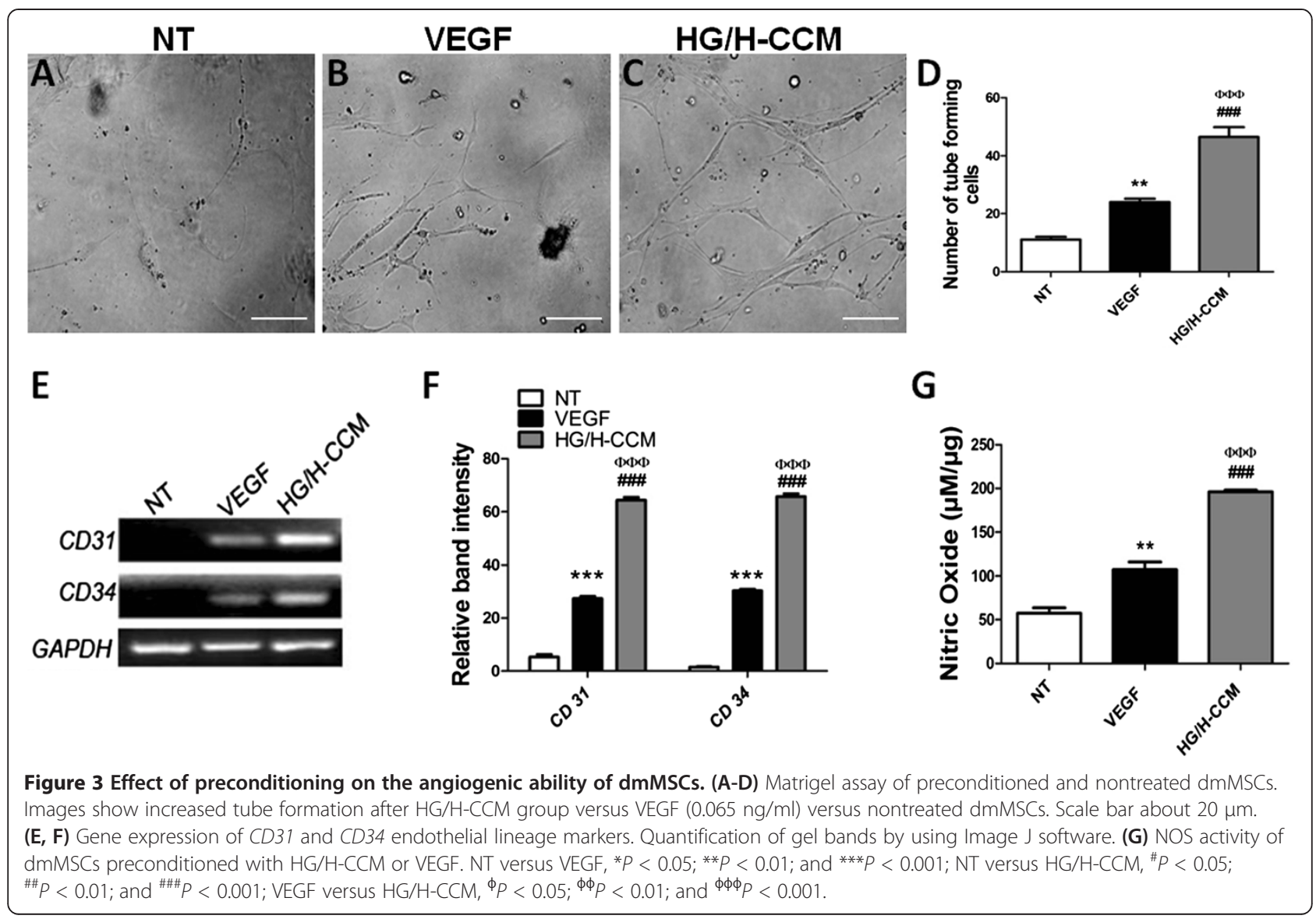

markers CD31 and CD34 was observed in the HG/HCCM group compared with VEGF and nontreated dmMSCs, as evidenced by gene-expression analysis (Figure 3E, F). Concurrently, dmMSCs showed significantly augmented NOS activity after 48 hours of preconditioning in $\mathrm{HG} / \mathrm{H}-\mathrm{CCM}(196 \pm 2.0 \mu M)$ treatment compared with VEGF $(107 \pm 8.8 \mu M)$ and nontreated dmMSCs $(57 \pm 6.3 \mu M)$ (Figure $3 G)$.

\section{Increased homing and paracrine signaling}

Increased survival of preconditioned dmMSCs was observed in diabetic animals 4 weeks after transplantation compared with nontreated MSCs, confirming the effect of preconditioning on dmMSC homing ability (Figure 4A to $C$ ). Analysis of paracrine factors demonstrated significant upregulation of IGF-1, FGF-2, SDF-1, and $H G F$ in group IV animals transplanted with dmMSCs preconditioned with HG/H-CCM compared with group III animals transplanted with nontreated dmMSCs (Figure 4D). Furthermore, gene-expression analysis demonstrated that group IV animals, transplanted with dmMSCs preconditioned with HG/H-CCM, exhibited significantly upregulated expression of VEGF, ANG-1, MEF2c, NKx2.5,
GATA-4, and $N F-\kappa B$, as evidenced by RT-PCR compared with group III animals transplanted with nontreated MSCs and diabetic control animals (Figure 4E, F).

\section{CCM preconditioning improves cardiac function}

Cardiac function of diabetic mice transplanted with HG/H-CCM preconditioned or nontreated dmMSCs was assessed after 4 weeks with the Millar apparatus (Figure 5A to D). Load-dependent-arameter ejection fraction (EF) revealed marked increases in group IV and group III as compared with group II. LV systolic function, as determined by $\mathrm{dp} / \mathrm{dt}_{\max }$ and $\mathrm{dp} / \mathrm{dt}_{\min }$, was significantly improved in group IV mice transplanted with HG/H-CCM preconditioned MSCs compared with group III mice that received nontreated dmMSCs. Collectively, a marked improvement was observed in the functionality of the diabetic heart after transplantation of the HG/H-CCM-preconditioned MSCs.

\section{CCM preconditioning enhances angiogenesis}

Diabetic heart transplanted with $\mathrm{HG} / \mathrm{H}-\mathrm{CCM}$-preconditioned MSCs showed significant improvement in diabetic myocardium. The number of blood vessels ( $\alpha$-SMA positive) was significantly increased in group IV 

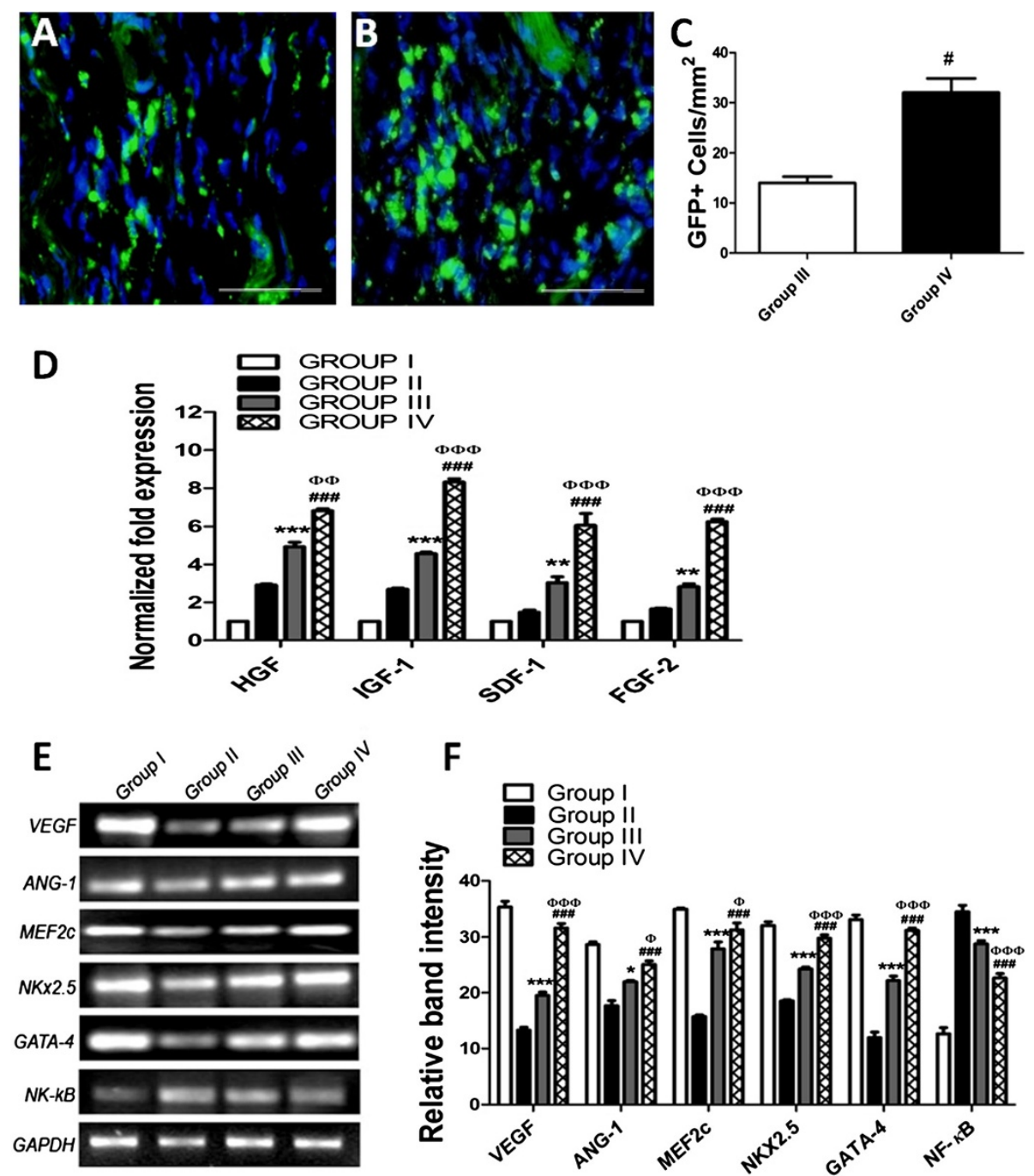

Figure 4 Increased homing and paracrine signaling of preconditioned dmMSCs. (A, B) Increased homing of preconditioned dmMSCS compared with nontreated MSCs along with corresponding quantification in (C); Scale bar about $20 \mu \mathrm{m}$. (D) Gene-expression analysis of paracrine factors in all animal groups by using quantitative real-time PCR. (E) Gene-expression analysis in hearts from all animal groups. (F) Gel quantification using image J. Group II versus group III, ${ }^{*} P<0.05$; ${ }^{*} P<0.01$, and ${ }^{* * *} P<0.001$; group II versus group IV, ${ }^{\#} P<0.05$; ${ }^{\# \#} P<0.01$; and $\# \# \#<0.001$; group III versus group IV, ${ }^{\phi} P<0.05 ; \phi \phi P<0.01$; and ${ }^{\phi} \phi \phi P<0.001$.

compared with group III mice $(21 \pm 0.001$ versus $13 \pm$ 0.001) (Figure 6A through E). Intense eNOS activity was observed in the cardiac tissue of group IV mice transplanted with $\mathrm{HG} / \mathrm{H}-\mathrm{CCM}$-preconditioned MSCs, whereas it was much weaker in the group III and II mice. Quantification of $\mathrm{eNOS}^{+}$cells confirmed significantly more cells in diabetic hearts treated with $\mathrm{HG} / \mathrm{H}$ CCM-preconditioned MSCs compared with all other groups (Figure 6F through $\mathrm{J}$ ). Immunostaining results for eNOS were confirmed with RT-PCR and demonstrated increased eNOS and reduced iNOS in group IV animals compared with groups III and II. GAPDH was used as cDNA quality and loading control (Figure 6K through L).

\section{Effect of CCM preconditioning on fibrosis}

dmMSCs preconditioned with HG/H-CCM demonstrated reduced fibrosis, as assessed with Masson trichrome staining (Figure 7A through E). Fibrosis 4 weeks after transplantation in animals was significantly lower in group IV $(4.7 \% \pm 0.60 \%)$ compared with group III $(15.4 \% \pm 0.94 \%)$ and group II mice $(20.1 \% \pm 1.18 \%)$.

\section{Effect of CCM preconditioning on apoptosis}

Analysis for apoptosis in all animal groups was done with cleaved caspase- 3 staining. Increased caspase- $3^{+}$cells were observed in group II $(43.2 \% \pm 2.85 \%)$ compared with group III $(28 \% \pm 2.5 \%)$ and group IV $(14.2 \% \pm 1.46 \%)$. As expected, lower apoptotic levels were found in the 

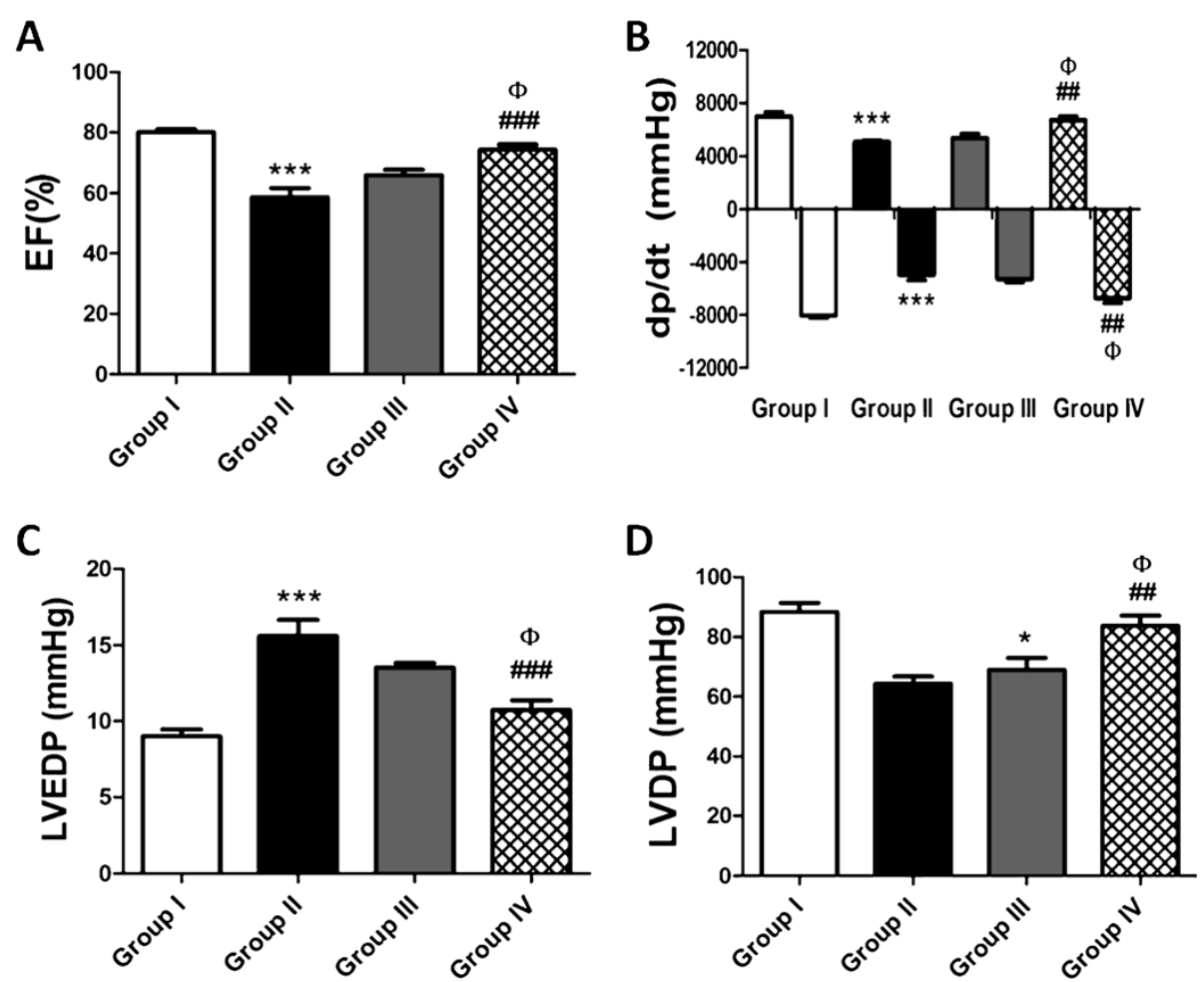

Figure 5 Cardiac function. Graphic representation of following parameters: (A) Ejection fraction (\%) in four groups. (B) dp/dt. (C and D) represent the left ventricle end-diastolic pressure and left ventricle diastolic pressure, respectively. Group II versus group III, ${ }^{*} P<0.05$; ${ }^{* *} P<0.01$; and ${ }^{* * *} P<0.001$; group II versus group IV, ${ }^{\#} P<0.05 ;{ }^{\# \#} P<0.01$; and ${ }^{\# \# \#} P<0.001$; group III versus Group IV, ${ }^{\phi} P<0.05 ;{ }^{\phi \phi} P<0.01$; and $\phi \phi \phi P<0.001$

diabetic myocardium transplanted with $\mathrm{HG} / \mathrm{H}-\mathrm{CCM}-$ preconditioned MSCs (Figure 7E through I).

\section{Discussion}

Diabetes mellitus is a major risk factor for development of myocardial infarction in a large segment of the population, causing an enormous economic burden. A number of studies have shown that diabetic hearts are more sensitive to ischemic insults that can lead to heart failure $[25,26]$. Development of diabetic cardiomyopathy is associated with decreased diastolic compliance, increased interstitial fibrosis, and myocyte hypertrophy [25]. Accrual of reactive oxygen species (ROS) in a diabetic heart leads to endothelium dysfunction characterized by vascular remodeling, disappearance of capillary endothelium, and altered gene and protein expression in endothelial cells [27]. Cell-based therapies using MSCs have been successfully used for treatment of the damaged heart, yet stem cells isolated from diabetic animals have severely reduced reparability [21], resulting in diminished heart repair after autologous transplantation [28]. Therefore, the present study demonstrated that preconditioning with HG/H-CCM can augment survival, proliferation, and angiogenic ability of MSCs isolated from streptozotocin-induced diabetic mice.
Bone marrow-derived MSCs have been shown to be the best candidates for myocardial regeneration and possess the ability to form cardiomyocytes, endothelial cells, and smooth muscle cells [29,30]. Adoptive transfer of MSCs in a rat model of diabetic cardiomyopathy is associated with enhanced angiogenesis, myogenesis, and cardiac function [31,32]. Nevertheless, the success of MSCs therapy for diabetic heart repair has been accompanied by reports of functional MSC decline as a consequence of diabetes. MSCs from streptozotocin-induced diabetic rats have impaired abilities for proliferation, paracrine, antiapoptosis, and myogenic differentiation [22]. Similarly, the onset of diabetes can attenuate the osteogenic differentiation ability of MSCs [33]. Therefore, augmentation of depleted MSC function becomes imperative if MSCs are to be used for autologous therapy to repair diabetic heart failure.

Preconditioning of stem cells with growth factors [23], hypoxic shock [34], and antiaging [35] compounds represents an effective strategy to enhance survival, proliferation, and differentiation of MSCs. Recent studies showed that ischemic preconditioning is a powerful regulator of cardioprotection [36-38], and we hypothesized that short-term stimulation of cardiomyocytes with a combination of stress stimuli can mimic in vitro the 

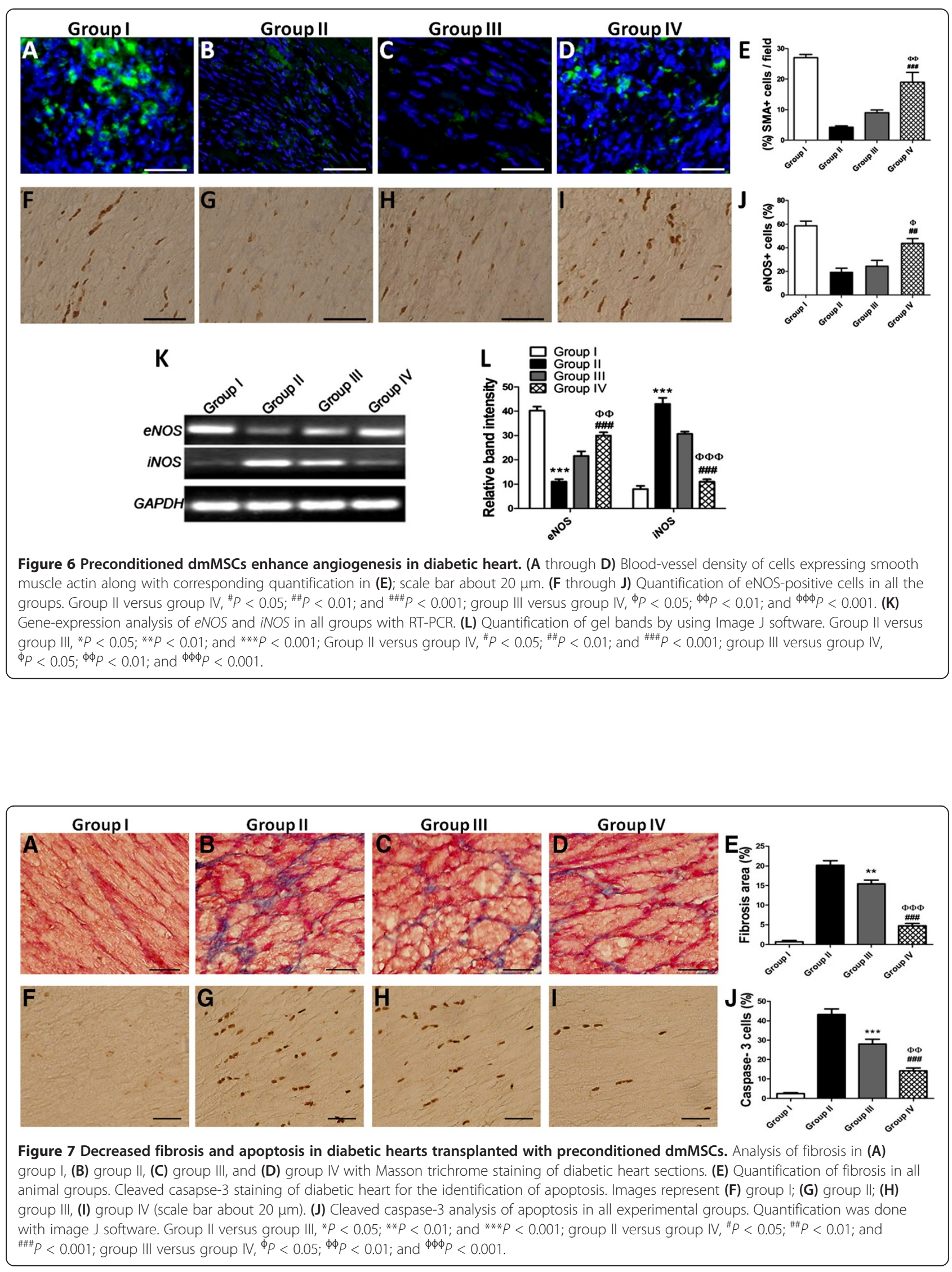
effects of ischemic preconditioning observed in vivo. Therefore, the normal and diabetic microenvironments of the myocardium were simulated in vitro by treating NRCMs with a combination of oxidative stress and high glucose, with the premise that treatment of dmMSCs with $\mathrm{HG} / \mathrm{H}-\mathrm{CCM}$ can enhance survival, proliferation, and importantly, increase the angiogenic ability of dmMSCs. We showed previously that diabetic mouse-derived MSCs have impaired proliferation, antioxidant levels, and survival signaling [23], meriting the need for preconditioning. Increased VEGF levels were observed in conditioned medium from NRCMs treated with $\mathrm{HG} / \mathrm{H}$ and concurs with previous reports showing upregulation of VEGF as a consequence of hypoxia [34]. In parallel to medium preconditioning, dmMSCs were preconditioned with VEGF alone to highlight that $\mathrm{HG} / \mathrm{H}-\mathrm{CCM}$ may contain other angiogenic and nonangiogenic paracrine factors, and these factors collectively can produce the optimal cellular response compared with treatment with VEGF alone.

dmMSCs were preconditioned with $\mathrm{HG} / \mathrm{H}-\mathrm{CCM}$ in parallel with VEGF. HG/H-CCM preconditioning significantly increased survival and proliferation of dmMSCs compared with treatment with VEGF alone and nontreated control. Our study also shows that the HG/HCCM preconditioning favors commitment of dmMSCs to the endothelial lineage, as confirmed by RT-PCR expression of endothelial lineage markers CD31 and CD34, concomitant with increased tube formation and nitric oxide production. These results concur with previous reports showing that oxidative stress can enhance recruitment [39], survival [34,40], migration [16], and differentiation [41] of MSCs. Furthermore, it has been shown that oxidative stress can augment the angiogenic potential of age-depleted bone marrow and adiposederived MSCs [42] and concurs with our observed results showing increased angiogenic ability of diabetic MSCs after preconditioning with $\mathrm{HG} / \mathrm{H}-\mathrm{CCM}$.

Adoptive transfer of $\mathrm{HG} / \mathrm{H}-\mathrm{CCM}$-preconditioned dmMSCs in diabetic animals showed augmented cardiac function and was concomitant with reduced collagen deposition and apoptosis, compared with nontreated dmMSCs and diabetic controls. Interestingly, transplantation of HG/H-CCM-preconditioned dmMSCs resulted in significant augmentation of angiogenesis in the diabetic heart, evidenced by increased $\mathrm{SMA}^{+}$cells and eNOS expression, whereas iNOS expression was significantly reduced compared with animals transplanted with nontreated dmMSCs and diabetic controls. Gene-expression analysis of hearts from animals transplanted with HG/ $\mathrm{H}$-CCM-preconditioned dmMSCs showed increased angiogenic (VEGF, ANG-1) and cardiac (MEF2c, GATA-4, $N K x 2.5)$ markers but decreased expression of $N F-\kappa B$ compared with animals with nontreated dmMSCs and diabetic controls. Conversely, increased paracrine factors (IGF-1,
$F G F-2, S D F-1, H G F)$ were found in the hearts of animals transplanted with CCM-preconditioned dmMSCs, supporting the idea that preconditioned dmMSCs have better survival, angiogenic ability, and can improve heart function by augmentation of a diabetic environment, possibly through a paracrine-mediated effect.

MSCs represent an attractive option for cell-based therapies for the repair of the diabetic heart. However, MSCs from a diabetic animal have attenuated ability to survive, proliferate, and repair the heart. Therefore, we showed that preconditioning with $\mathrm{HG} / \mathrm{H}-\mathrm{CCM}$ can augment survival, proliferation, and the angiogenic ability of dmMSCs. Furthermore, adoptive transfer of dmMSCs preconditioned with $\mathrm{HG} / \mathrm{H}-\mathrm{CCM}$ improves cardiac function and angiogenesis while reducing fibrosis and apoptosis in the diabetic heart, possibly through a paracrine effect. Thus, preconditioning of dmMSCs represents an effective strategy to improve depleted MSC function and holds promise for the treatment of diabetic heart failure.

\section{Conclusions}

We demonstrated that preconditioning with cardiomyogenic medium can improve survival, proliferation, and cardiac-repair ability of dmMSCs. Development of diabetes mellitus has been shown to attenuate MSC survival, proliferation, and the ability to repair the heart after myocardial infarction. Preconditioning strategies consist of growth factors, hypoxia, and other factors and can augment depleted stem-cell function to repair damaged organs. We used a preconditioning strategy based on medium from cardiomyocytes treated with oxidative stress and high glucose, with the premise that acute exposure to stress can stimulate cardiomyocytes to release paracrine factors in the medium. Preconditioning of dmMSCs with medium rich in paracrine factors from the cardiomyocytes increased survival, proliferation, and angiogenic ability to dmMSCs. Therefore, we report here a viable strategy to enhance dmMSC function and increase repair of diabetic myocardium.

\section{Abbreviations}

CCM: Conditioned cardiomyogenic medium; dmMSCs: diabetic mousederived mesenchymal stem cells; $d p / d t_{\text {max }}$ : Maximal change in pressure/ change in time; $\mathrm{dp} / \mathrm{dt}_{\mathrm{min}}$ : Minimal change in pressure/change in time; $\mathrm{HG} / \mathrm{H}$ : High-glucose $/ \mathrm{H}_{2} \mathrm{O}_{2} ; \mathrm{HG} / \mathrm{H}-\mathrm{CCM}$ : High-glucose $/ \mathrm{H}_{2} \mathrm{O}_{2}$-conditioned cardiomyogenic medium; IMDM: Iscove modified Dulbecco medium; LDH: Lactate dehydrogenase; LG/H: Low-glucose $/ \mathrm{H}_{2} \mathrm{O}_{2} ;$ LV: Left ventricle; MSCs: Mesenchymal stem cells; NOS: Nitric oxide synthase; NRCM: Neonatal rat cardiomyocytes; $P_{\text {max }}$ : Maximal pressure; ROS: Reactive oxygen species; SMA: Smooth muscle actin.

\section{Competing interests}

The authors have no financial conflicts of interest.

\section{Authors' contributions}

MK carried out cardiomyocyte isolation, participated in study design, and drafted the manuscript. FA performed in vitro assays, in vivo studies, and drafted the manuscript. SM participated in study design, statistical analysis, and helped draft the manuscript. SA participated in generating the diabetic 
mouse model. AM carried out microscopy. MSC performed invasive hemodynamic procedures. SNK participated in study design and drafted the manuscript. SR conceived the study, participated in study design, and drafted the manuscript. All authors read and approved the final manuscript.

\section{Acknowledgements}

We thank our colleagues for the review of this manuscript. This work was supported by research grants from the Higher Education Commission (HEC) of Pakistan.

Received: 22 November 2012 Revised: 21 April 2013

Accepted: 16 May 2013 Published: 24 May 2013

\section{References}

1. From AM, Scott CG, Chen HH: The development of heart failure in patients with diabetes mellitus and pre-clinical diastolic dysfunction a population-based study. J Am Coll Cardiol 2010, 55:300-305.

2. Geraldes $P$, King GL: Activation of protein kinase $C$ isoforms and its impact on diabetic complications. Circ Res 2010, 106:1319-1331.

3. Jarajapu YP, Grant MB: The promise of cell-based therapies for diabetic complications: challenges and solutions. Circ Res 2010, 106:854-869.

4. van den Oever IA, Raterman HG, Nurmohamed MT, Simsek S: Endothelial dysfunction, inflammation, and apoptosis in diabetes mellitus. Mediators Inflamm 2010, 2010:792393.

5. Boodhwani M, Sodha NR, Mieno S, Xu SH, Feng J, Ramlawi B, Clements RT, Sellke FW: Functional, cellular, and molecular characterization of the angiogenic response to chronic myocardial ischemia in diabetes. Circulation 2007, 116:131-137.

6. Krause DS: Plasticity of marrow-derived stem cells. Gene Ther 2002, 9:754-758.

7. Vieyra DS, Jackson KA, Goodell MA: Plasticity and tissue regenerative potential of bone marrow-derived cells. Stem Cell Rev 2005, 1:65-69.

8. Sharif S, Nakagawa T, Ohno T, Matsumoto M, Kita T, Riazuddin S, Ito J: The potential use of bone marrow stromal cells for cochlear cell therapy. NeuroReport 2007, 18:351-354.

9. Trivedi P, Tray N, Nguyen T, Nigam N, Gallicano Gl: Mesenchymal stem cell therapy for treatment of cardiovascular disease: helping people sooner or later. Stem Cells Dev 2010, 19:1109-1120.

10. Cook MM, Kollar K, Brooke GP, Atkinson K: Cellular therapy for repair of cardiac damage after acute myocardial infarction. Int J Cell Biol 2009, 2009:906507.

11. Kretlow JD, Jin YQ, Liu W, Zhang WJ, Hong TH, Zhou G, Baggett LS, Mikos $A G, C a o$ Y: Donor age and cell passage affects differentiation potential of murine bone marrow-derived stem cells. BMC Cell Biol 2008, 9:60.

12. Li X, Liu L, Meng D, Wang D, Zhang J, Shi D, Liu H, Xu H, Lu L, Sun L: Enhanced apoptosis and senescence of bone-marrow-derived mesenchymal stem cells in patients with systemic lupus erythematosus. Stem Cells Dev 2012, 21:2387-2394.

13. Alt EU, Senst C, Murthy SN, Slakey DP, Dupin CL, Chaffin AE, Kadowitz PJ, Izadpanah R: Aging alters tissue resident mesenchymal stem cell properties. Stem Cell Res 2012, 8:215-225.

14. Khan M, Mohsin S, Khan SN, Riazuddin S: Repair of senescent myocardium by mesenchymal stem cells is dependent on the age of donor mice. J Cell Mol Med 2011, 15:1515-1527.

15. Hahn JY, Cho HJ, Kang HJ, Kim TS, Kim MH, Chung JH, Bae JW, Oh BH, Park YB, Kim HS: Pre-treatment of mesenchymal stem cells with a combination of growth factors enhances gap junction formation, cytoprotective effect on cardiomyocytes, and therapeutic efficacy for myocardial infarction. J Am Coll Cardiol 2008, 51:933-943.

16. Rosova I, Dao M, Capoccia B, Link D, Nolta JA: Hypoxic preconditioning results in increased motility and improved therapeutic potential of human mesenchymal stem cells. Stem Cells 2008, 26:2173-2182.

17. Peterson KM, Aly A, Lerman A, Lerman LO, Rodriguez-Porcel M: Improved survival of mesenchymal stromal cell after hypoxia preconditioning: role of oxidative stress. Life Sci 2011, 88:65-73.

18. Liu H, Xue W, Ge G, Luo X, Li Y, Xiang H, Ding X, Tian P, Tian X: Hypoxic preconditioning advances CXCR4 and CXCR7 expression by activating HIF-1alpha in MSCs. Biochem Biophys Res Commun 2010, 401:509-515.

19. Xie XJ, Wang JA, Cao J, Zhang X: Differentiation of bone marrow mesenchymal stem cells induced by myocardial medium under hypoxic conditions. Acta Pharmacol Sin 2006, 27:1153-1158.
20. Kubo M, Li TS, Kurazumi H, Takemoto Y, Ohshima M, Murata T, Katsura S, Morikage N, Furutani A, Hamano K: Hypoxic preconditioning enhances angiogenic potential of bone marrow cells with aging-related functional impairment. Circ J 2012, 76:986-994.

21. Rota M, LeCapitaine N, Hosoda T, Boni A, De Angelis A, Padin-Iruegas ME, Esposito G, Vitale S, Urbanek K, Casarsa C, Giorgio M, Luscher TF, Pelicci PG, Anversa P, Leri A, Kajstura J: Diabetes promotes cardiac stem cell aging and heart failure, which are prevented by deletion of the p66shc gene. Circ Res 2006, 99:42-52.

22. Jin $P$, Zhang $X, W u Y$, Li L, Yin $Q$, Zheng $L$, Zhang $H$, Sun $C$ Streptozotocin-induced diabetic rat-derived bone marrow mesenchymal stem cells have impaired abilities in proliferation, paracrine, antiapoptosis, and myogenic differentiation. Transplant Proc 2010, 42:2745-2752

23. Khan M, Akhtar S, Mohsin S, Khan SN, Riazuddin S: Growth factor preconditioning increases the function of diabetes-impaired mesenchymal stem cells. Stem Cells Dev 2011, 20:67-75.

24. Choudhery MS, Khan M, Mahmood R, Mohsin S, Akhtar S, Ali F, Khan SN, Riazuddin S: Mesenchymal stem cells conditioned with glucose depletion augments their ability to repair infarcted myocardium. $J$ Cell Mol Med 2012, 16:2518-2529.

25. Aronson D, Musallam A, Lessick J, Dabbah S, Carasso S, Hammerman H, Reisner S, Agmon Y, Mutlak D: Impact of diastolic dysfunction on the development of heart failure in diabetic patients after acute myocardial infarction. Circ Heart Fail 2010, 3:125-131.

26. Vassort G, Turan B: Protective role of antioxidants in diabetes-induced cardiac dysfunction. Cardiovasc Toxicol 2010, 10:73-86.

27. Hayat SA, Patel B, Khattar RS, Malik RA: Diabetic cardiomyopathy: mechanisms, diagnosis and treatment. Clin Sci (Lond) 2004, 107:539-557.

28. Govaert JA, Swijnenburg RJ, Schrepfer S, Xie X, van der Bogt KE, Hoyt G, Stein W, Ransohoff KJ, Robbins RC, Wu JC: Poor functional recovery after transplantation of diabetic bone marrow stem cells in ischemic myocardium. J Heart Lung Transplant 2009, 28:1158-1165. e1151.

29. Quevedo HC, Hatzistergos KE, Oskouei BN, Feigenbaum GS, Rodriguez JE, Valdes D, Pattany PM, Zambrano JP, Hu Q, McNiece I, Heldman AW, Hare $J M$ : Allogeneic mesenchymal stem cells restore cardiac function in chronic ischemic cardiomyopathy via trilineage differentiating capacity. Proc Natl Acad Sci U S A 2009, 106:14022-14027.

30. Huang Y, Zheng L, Gong X, Jia X, Song W, Liu M, Fan Y: Effect of cyclic strain on cardiomyogenic differentiation of rat bone marrow derived mesenchymal stem cells. PLoS One 2012, 7:e34960.

31. Zhang N, Li J, Luo R, Jiang J, Wang JA: Bone marrow mesenchymal stem cells induce angiogenesis and attenuate the remodeling of diabetic cardiomyopathy. Exp Clin Endocrinol Diabetes 2008, 116:104-111.

32. Abdel Aziz MT, El-Asmar MF, Haidara M, Atta HM, Roshdy NK, Rashed LA, Sabry D, Youssef MA, Abdel Aziz AT, Moustafa M: Effect of bone marrowderived mesenchymal stem cells on cardiovascular complications in diabetic rats. Med Sci Monit 2008, 14:BR249-BR255.

33. Stolzing A, Sellers D, Llewelyn O, Scutt A: Diabetes induced changes in rat mesenchymal stem cells. Cells Tissues Organs 2010, 191:453-465.

34. Chacko SM, Ahmed S, Selvendiran K, Kuppusamy ML, Khan M, Kuppusamy $P$ : Hypoxic preconditioning induces the expression of prosurvival and proangiogenic markers in mesenchymal stem cells. Am J Physio/ Cell Physiol 2010, 299:C1562-C1570.

35. Robich MP, Osipov RM, Nezafat R, Feng J, Clements RT, Bianchi C, Boodhwani M, Coady MA, Laham RJ, Sellke FW: Resveratrol improves myocardial perfusion in a swine model of hypercholesterolemia and chronic myocardial ischemia. Circulation 2010, 122:S142-S149.

36. Wang Y, Hirai K, Ashraf M: Activation of mitochondrial ATP-sensitive $\mathrm{K}(+)$ channel for cardiac protection against ischemic injury is dependent on protein kinase C activity. Circ Res 1999, 85:731-741.

37. Miura T, Liu Y, Goto M, Tsuchida A, Miki T, Nakano A, Nishino Y, Ohnuma Y, Shimamoto K: Mitochondrial ATP-sensitive $\mathrm{K}+$ channels play a role in cardioprotection by $\mathrm{Na}+-\mathrm{H}+$ exchange inhibition against ischemia/ reperfusion injury. J Am Coll Cardiol 2001, 37:957-963.

38. Wojtovich AP, Urciuoli WR, Chatterjee S, Fisher AB, Nehrke K, Brookes PS: KIR 6.2 is not the mitochondrial KATP channel, but is required for cardioprotection by ischemic preconditioning. Am J Physiol Heart Circ Physiol 2013. doi:10.1152/ajpheart.00972.2012.

39. Liu H, LiU S, Li Y, Wang X, Xue W, Ge G, Luo X: The role of SDF-1-CXCR4/ CXCR7 axis in the therapeutic effects of hypoxia-preconditioned 
mesenchymal stem cells for renal ischemia/reperfusion injury. PLoS One 2012, 7:e34608.

40. Hu X, Yu SP, Fraser JL, Lu Z, Ogle ME, Wang JA, Wei L: Transplantation of hypoxia-preconditioned mesenchymal stem cells improves infarcted heart function via enhanced survival of implanted cells and angiogenesis. J Thorac Cardiovasc Surg 2008, 135:799-808.

41. Volkmer E, Kallukalam BC, Maertz J, Otto S, Drosse I, Polzer H, Bocker W, Stengele M, Docheva D, Mutschler W, Schieker M: Hypoxic preconditioning of human mesenchymal stem cells overcomes hypoxia-induced inhibition of osteogenic differentiation. Tissue Eng Part A 2010, 16:153-164.

42. Efimenko A, Starostina E, Kalinina N, Stolzing A: Angiogenic properties of aged adipose derived mesenchymal stem cells after hypoxic conditioning. J Trans/ Med 2011, 9:10.

doi:10.1186/scrt207

Cite this article as: Khan et al:: Preconditioning diabetic mesenchymal stem cells with myogenic medium increases their ability to repair diabetic heart. Stem Cell Research \& Therapy 2013 4:58.

\section{Submit your next manuscript to BioMed Central and take full advantage of:}

- Convenient online submission

- Thorough peer review

- No space constraints or color figure charges

- Immediate publication on acceptance

- Inclusion in PubMed, CAS, Scopus and Google Scholar

- Research which is freely available for redistribution 